\title{
OLYMPIC EDUCATION IN THE EDUCATIONAL PROCESS OF UKRAINE (IN THE CASE OF BUCOVYNA)
}

\section{Hakman Anna ${ }^{1}$ \\ Nakonechnyi Ihor ${ }^{2}$}

http://dx.doi.org/10.30525/978-9934-571-27-5_12

Abstract. In recent decades, in various spheres of society, and especially in pedagogy is increasing interest in philosophical, sociological and cultural aspects of the theory and practice of the Olympic movement, an important component of which is Olympic education, based on the ideas of Olympism. Olympic education is an effective means of humanizing the system of education and upbringing of the younger generation, aimed at forming humanistic-oriented personality traits, and therefore, the problem of spiritual and moral condition of children and young people, due to socio-cultural changes that accompany the formation of Ukraine as a democratic state.

The purpose of our investigation is to theoretically substantiate the peculiarities of the formation of Olympic education in schools at different levels, which will facilitate its better implementation in Ukrainian society. The research was conducted during 2016-2017 at the educational institutions of Chernivtsi city.

In the investigation took part 75 respondents, 25 of which were instructors of physical education in the pre-school educational institutions, 25 - teachers of physical education and 25 - teachers of physical education at university level.

Methods of research: theoretical analysis and generalization of literary sources, conversation, method of expert estimation, methods of mathematical statistics.

During the research, the main preconditions for forming the pedagogical foundations of the Olympic education in Ukraine were determined. The structure of the Olympic education in the educational process is analyzed.

\footnotetext{
${ }^{1}$ Ph.D. in Physical Education and Sports,

Associate Professor at the Department of Theory and Methods of Physical Education and Sports, Yuriy Fedkovych Chernivtsi National University, Ukraine

${ }^{2}$ Ph.D. in Psychology,

Head of the Department of Theory and Methods of Physical Education and Sports,

Yuriy Fedkovych Chernivtsi National University, Ukraine
} 


\section{Olympic education in the educational process of Ukraine (in the case of...}

The condition of readiness for the introduction of Olympic education in Chernivtsi is determined. According to the investigation, it can be argued that the highest state of implementation of the Olympic education in Bukovyna is at school level. Respondents define the main disadvantages in the implementation of Olympic education in pre-school institutions: poor knowledge of specialists, lack of material and technical base, insufficient methodological support.

In the course of the investigation, the main reasons for ineffective implementation of the Olympic education were identified. A comparative analysis of Olympic education in schools of Chernivtsi, which takes into account all levels of education, from pre-school to higher educational establishments, was carried out.

The main mechanism for the implementation of pedagogical activities is the creation of pedagogical situations, during which there is the possibility of interaction between a student and a teacher, which allows to evoke reflexive attitude of the student to the means of influence of the teacher. The pedagogical situation serves as the basis for pedagogical communications that provide the transfer and mastering of the knowledge. To achieve the goal of teaching and upbringing, a modern teacher should identify and apply the most effective forms and methods. Therefore, we identified the forms and means of implementing the Olympic education for various educational institutions.

Consequently, according to respondents, the introduction of Olympic education will contribute to the improvement of the system of physical education and educational process; the ideals of Olympism and the values of the Olympic movement can become an important part of the concept of the educational work of the modern schools.

Most teachers are willing to implement Olympic education in schools, but there is a need of scientific and methodological assistance. The responders determined the most acceptable forms of the introduction of Olympic education in the educational process during lessons and in extra time.

\section{Introduction}

Creation of a modern system of education and upbringing of the younger generation is impossible without the optimal solution to a range of social, economic, environmental, political, legal and other tasks. One solution to this difficult problem may be the organization of an educational process based on 
the ideology of Olympism, through the introduction of a system of Olympic education and the distribution of literature among the student youth.

Olympic education today is not only a significant factor in the development of the Olympic movement in Ukraine, but also a powerful tool for solving the strategic challenges facing the country, and, above all, an important component of the humanitarian education aimed at the formation of physical and moral health among Ukrainians, healthy lifestyle habits, engaging them in physical education and sports, especially the younger generation.

The relevance of Olympic education is determined by the following circumstances.

Firstly, the involvement of children in the world of sport, formation of their active attitude to physical culture and sports are priorities, that largely determine the level of health of the younger generation. Olympic education, which is based on the attractiveness of the Olympic Games, peculiar to them, spectacle and adversity, has considerable potential for solving this problem, on vivid examples of the lives of famous athletes. It is capable of attracting and encouraging young people to go in for sports. Secondly, educational institutions cover a significant part of the younger generation. It is there, where they begin to form habits, beliefs, interests in one or another type of activity and lifestyle. Therefore, much depends on the effectiveness of the educational process, which, due to important changes in social life, has lost its humanistic direction. An important role in this situation is played by the Olympic education, which, in solving the problems of education, is based on humanistic ideals and principles of Olympism.

Combining sport activity and motor activity with culture and education, the ideas of Olympism promote the way of life, which is based on the joy of efforts, the educational value of a good example, and respect for universal, fundamental ethical principles. That is why, in the current conditions, the Olympic education that has the potential to increase the effectiveness of the formation of a physically, mentally, socially and spiritually healthy personality has gained special significance [28, p. 90; 6, p. 7].

The topicality of the chosen direction of research is also enhanced by the fact that in Ukraine, as a country, which is an active participant in the international Olympic movement, there is an urgent need for the deployment of this type of activity, the investigation of the content component of the school curriculum of the Olympic education is required, the effectiveness 
of the organization and the form of introduction of knowledge of the Olympic theme. In this regard, it is important to identify ways of implementing appropriate measures in the system of school Olympic education in Ukraine.

The aim of the research is to theoretically substantiate the peculiarities of the formation of Olympic education in educational institutions, which will facilitate its implementation.

The achievement of the aim stipulates the solution of the following objec-tives:

1. To analyze the status and implementation of the Olympic education in the educational process of Ukraine on the example of Bukovyna.

2. To carry out a comparative analysis of the implementation of the Olympic education in various types of educational institutions of Chernivtsi city.

The research rests upon the following research methods: theoretical analysis and generalization of scientific and methodical literature, conversation, method of expert evaluation, methods of mathematical statistics.

\section{Formation of pedagogical foundations of Olympic education in Ukraine}

The Contemporary International Olympic Movement, after the Eleventh Olympic Congress in Baden-Baden in 1981, also began to lean toward commercialization by abolishing the status of an amateur athlete.

Without making socio-political assessments, we note the similarity of the phenomena of the ancient and modern world - the appearance of athletes-professionals, sports show business and other negative phenomena. It should be mentioned, that in ancient Greece, attention was drawn to the negative manifestations of unnecessary enthusiasm for preparation and participation in competitions. For example, Euripides noted that the monotonous specialized diet of athletes does not promote normal lifestyle. This is also pointed out by Hippocrates, who said that monotonous workouts and a diet pose a danger to human physiology, lead to its degradation; excessive muscle development violates symmetry, leads to physical destabilization, lag, and weakening of other abilities" [24, p. 135].

For several centuries, the ancient ideals of Olympism, as a cultural phenomenon of pedagogy, were forgotten to be revived in a democratic France at the end of the 19th century. Due to the achievements of the science of physical culture, initiatives of an organizational nature and the initiation of competitions, France at the end of the XIX century became the spiritual 
center of international life. As a result, the French sports movement not only carried out the tendency for international integration, but also contributed to the emergence of a person such as Pierre de Coubertin. His work is devoted to dozens of papers written by scholars and publicists in many countries, but there is a need to turn again to the personality of Baron Coubertin, his rich artistic heritage.

Over 50 years of his life, Coubertin devoted to Olympism, and for 29 years he was the president of the International Olympic Committee (IOC).

During his presidency, the most important events, that have enriched the practice of Olympism, were held: he is the author of the first version of the Olympic Charter, on his initiative was the registration of the Olympic protocol, many rituals and symbols of the Olympic Games were implemented into practice.

Coubertin owns the idea of the holding the Olympic Games in different countries and on different continents. At his initiative, the Olympic congresses were held, and during his life 9 of 12 has taken place, where various scientific problems of Olympism were discussed. It was he, who suggested the idea of creating the Olympic Academy in Olympia. Coubertin's creative legacy is so large that only in recent years leading specialists of our country are engaged in studying it.

In the "Evolution of Olympic Ideas" professor V. V. Stolbov (1996) claims, that the greatness of Coubertin, was manifested in the determination and development of the philosophical, moral and ideological principles of Olympism, which should carry the idea of peace, friendship and cooperation among peoples [24, p. 22]. He always cared about the development in the Olympism of the ideas of democracy and internationalism. Coubertin was against racism and militarism, any discrimination on property and religious grounds. The decisive role of the Olympic sport Coubertin saw in the harmonious development of personality. He dreamed about the time when the sport would be available to millions of ordinary people, not to ones from wealthy families. Coubertin argued that the future belongs to the people who will be the first to reorganize the education of the younger generation. From each sports facility, which deals with young people, must come the joy of physical and spiritual strength. Coubertin made a huge contribution to the development of theoretical and pedagogical foundations of modern Olympism. He believed, that Olympism should unite together, complementing each other, sports, culture, science and art. 


\section{Olympic education in the educational process of Ukraine (in the case of...}

It should be mentioned, that the predictions of Coubertin remained not only in a fantasy of a humanist, but found a convincing confirmation in the history of modern Olympism. Over 100 years of its development, the Olympic Games have evolved from a simple sporting holiday and the aspirations of enthusiasts into a complex social scientific and practical movement of nations of the world.

Coubertin laid the foundation to the scientific substantiation of a special subject, which he called "sports pedagogy". In 1934 the third edition of the book with the same name was published. He regarded this discipline as a science of physical education and upbringing of youth through sport. By the same token, Coubertin foresaw the appearance of later Olympic education and the upbringing of the younger generation.

Coubertin has expressed the opinion that the secret of growth and decline of any democracy should be constantly searched in school, university. He proposed to increase the intensity of physical activity of students, but without prejudice to intellectual development. Coubertin suggested, sports pedagogy is a good starting point for the Olympic movement. The significance of sports pedagogy, according to Coubertin, should serve to social progress. He expressed this idea perfectly and convincingly in his "Ode Sport".

According to professor V. I. Stolyarov (1996), when developing the concept of Olympism, Coubertin took into account the humanistic potential of sport, and at the same time, the dual role that sport can play in society. Sports can contribute to the preservation and strengthening of human health, its physical improvement, the formation and development of high morality, aesthetic culture, etc. [25, p. 120]. However, sports training and competitions under certain conditions can have a negative impact on human health, capable of developing a person's cruelty, a sense of mental superiority over others.

Coubertin wrote: "Athleticism can occasion the most noble passions or the most vile. It can be chivalrous or corrupt, vile, bestial".

Therefore, Coubertin believed, the main task of the Olympic movement is not only the development of sport, but contribution in every way to the realization of its humanistic potential. An important task of Olympism, he saw in overcoming the gap between physical and spiritual development of the athlete, in contributing to its versatile and harmonious development.

Coubertin advocated supporting the Olympians' desire for high achievements in sports, but emphasized, that there is a certain limit that can not be 
passed within the framework of the Olympic Games, no matter what desirable victory is present.

Such a limit Coubertin considered first of all ethical rules: an olympic player should not strive for victory at all costs, but prefer honest, chivalrous behavior in sporting matches. He must adhere to the conviction that the most important thing is not the victory over the rival, but the courage that manifests itself in the struggle for this victory.

Coubertin predicted the emergence of the Olympic education and the up-bringing of the younger generation, which appeared later, Coubertin sought to educate the youth in courage, without which a national growth is impossible. He was referring to the problem of strengthening the French nation, although his position is entirely relevant to any other.

A comprehensive analysis of the work of Pierre de Coubertin allows from a wide range of scientific and theoretical interests to distinguish three fundamental blocks, three main directions of its reformist activity:

- aspects of pedagogy, system of education and upbringing;

- Olympism, Olympic movement, Olympic Games;

- sport, sports movement.

Highlighted areas of reformation of Coubertin's are deeply interconnected and interdependent [26, p. 42].

All ideas, which were put forward by Coubertin and realized under his direction in connection with the Olympic movement, were of an innovative nature. These directions of Pierre de Coubertin's work are carefully and thoroughly analyzed in the work of Professor A.B. Sunik (1995), with whose point of view one can agree [26, p. 48].

Evaluating the reform activity of Coubertin, it must be admitted that many of his ideas were embodied in the world theory and practice in the spheres of pedagogy of the sports and olympic movement. But now, in the new XXI century, it becomes more obvious, how the humanitarian ideas of Coubertin are necessary to the world community.

The opinion of Coubertin: "A significant part of the national programs refers to the issue of education,» is now very relevant. Therefore, we propose to consider his educational ideas of Olympism in the further work upon the Olympic education and upbringing. Based on this understanding of sport, Coubertin made a lot of efforts to create conditions that would enable them to effectively use the humanistic, educational, educational potential embodied in sport; sought to combine sport with science, art, literature. 


\section{Olympic education in the educational process of Ukraine (in the case of...}

The emphasis on this aspect of Coubertin's work allows us to comprehend deeper the essence of the Olympic idea - the priority of educational, educational function, its humanistic and democratic orientation in it.

It can now be argued, that the philosophy of Olympism, its spiritual culture is far behind the practice of modern games. The rapid development of games, the growth of their sphere of influence and popularity undermined, to a certain extent, the basis of the Coubertin's concept of Olympism.

During the development of the Olympic Games, in the practice of their conducting, concepts that contradict the ideas of Coubertin are increasingly introduced: professionalization, unlimited commercialization, the problem of doping, and so on.

One can assume that the Olympic mottoes has come into conflict with each other: on one hand "The most important thing is not winning but taking part!" and on the other hand "Faster, Higher, Stronger!".

They were well-matched in those times of the history of the Olympic Games, when sport was not a profession for an athlete, but served as a form of recreation, entertainment. By affirming these Olympic mottoes, their creators could not think that they would pay huge sums for winning the Olympic Games, and sports would become a profession.

Thus, this contradiction is nothing but a contradiction between amateur and professionalism in the Olympic sport. In the existing Olympic philosophy, this problem is mainly viewed from a moral and ethical point of view. For an amateur in sports, the motto "Victory at all costs" is completely rejected, whereas for a professional this motto forms the basis of his life position. Where this motto is decisive, all ethical and moral principles cease to apply.

We can assume, that such a situation in the modern Olympic movement arose due to the following reasons:

- significant progress in the development of society has led to a change in the social function of sport, which has not been taken into account for a long time;

- delay in development of the modern concept of Olympism, reflecting changes in society and sport;

- aggravation of contradictions between the existing philosophy of Olympism and the practice of contemporary Olympic games.

These problems are becoming a new object of scientific research.

Originated in France, the Olympic ideas spread in various regions of tsarist Russia, including Ukraine. 
Study of the influence of motor activity and sports on health, culture, education of children and young people in different countries allowed Coubertin to form an appropriate attitude to the Olympic sport as a means of upbringing the younger generation.

He believed, that Olympism combines sport with culture and education, due to its expressed humanistic potential, serves as an ideological and moral basis for the process of educating the younger generation. Thus, predicted the emergence of Olympic education.

It should be noted, that the fundamentals of Olympic education were also laid by P. Coubertin in the "Sports Pedagogy" (1919), and the term "Olympic education" was used in the second half of the twentieth century.

Subsequently, the relevant discipline was introduced into the educational process of higher educational institutions. The idea of harmonious human development has become the key value of Olympism.

The stage of the formation and development of the Olympic education began with the creation of the International Olympic Committee, the holding of the Session in 1897 (Havre, France), where the issues of the Olympic education were raised for the first time. With the opening of the International Olympic Academy (IOA) in 1961, the conception of the importance of Olympic education in the modern world has changed. The urgency of the development of this direction contributed to the creation of the IOC Special Commissions for Culture and Olympic Education in 2000. It was created as a result of the merger of two previous ones: the IOC Commission from the IOA and the Olympic Education (1967) and the IOC Commission on Culture (1968). Subsequently, to these organizations, that deal with the spread of olympism, joined the International Committee of P. de Coubertin, the international and national centers of olympic research and education, the organizing committees of the Olympic Games (OCOG), the national Olympic academies (NOA), and others. [10, p. 40].

Since the mid-90s of the 20th century, Ukraine has taken a prominent position in popularizing, implementing the Olympic education, enriching its content and forms.

The leading role in shaping the national model of implementation of Olympic education belongs to the Olympic Academy of Ukraine (OAU) and one of the world's leading specialized universities - the National University of Physical Education and Sport in our country. 


\section{Olympic education in the educational process of Ukraine (in the case of...}

In Ukraine, a fundamentally developed system of Olympic education, the implementation of which is carried out in two main areas: general education and special education (M.M. Bulatova, V.N. Platonov, 1998-2005) [11, p. 7; 23, p. 494].

It is based on the successful implementation of 10-year International Pro-gram of scientific research, educational and publishing activities in the field of Olympic sports, done by the OAU together with the National University of Physical Education and Sport. The program has been highly appreciated by the IOC leadership, leading experts all around the world.

Among the main directions of the development of Olympic education, scientific and pedagogical activities in Ukraine, one can distinguish: the introduction of the new specialty "Olympic and professional sports" in the Ukrainian National University of Physical Education and Sport, the creation of the first department in the world with the same name, the special publication of "Olympic literature", publishing under the auspices of the IOC of fundamental research done by V.N. Platonov and S.I. Guskova "Olympic sport" (1994) in 2 volumes and "Encyclopedia of Olympic sport" (2002-2004) in 5 volumes, the publication of the international scientific and theoretical journal "Science in Olympic sports", the creation of the National and regional centers of olympic research and education, organization and holding of "Olympic lessons" in schools of Ukraine, development and publication of educational-cognitive literature for pupils with an Olympic theme, etc. [7, p. 40; 23]

The issue of the history of the Olympic movement were worked out by the ukrainian authors: A.O. Bodnar (2014), V.M. Ermolova (2011), Ya. Galan (2015), A. Hakman (2017), I. Hruzevych (2017), O. Ivashchenko (2017), I. Nakonechnyi (2017), O. Tomenko (2008), O. Yarmak (2017), Ya. B. Zoriy (2016), and be foreign researchers: L.I. Lubysheva (2007), V.V. Stolbov (1996), V.I. Stolyarov \& I.V. Barinova (2002), A.B. Sunik (1991) etc. Problems of the genesis of Olympism, the periodization of the Olympic Games, and their social significance were explored by L. Balatskaya (2016), I. Gorshova (2017), A.V. Hakman (2017), L.I. Lubysheva (2007) and others.

Starting from 2013, the Olympic Academy of Ukraine together with the NOC of Ukraine, the IOC of Ukraine and the Ministry of Youth and Sports of Ukraine announces the All-Ukrainian contest for the best model of the school organization implementing Olympic education in the educational 
process among the schools of the project "Olympic Education" for the purpose of finding effective forms and methods for implementing the Olympic education in the educational process.

According to M. Bulatova, the active implementation of the ideology of Olympism in the general population, and, above all, in educational institutions, allows to counteract the negative influence of the street, the media, to counter social diseases, to promote the needs of physical culture and sports, a healthy lifestyle, refusal of bad habits, which in turn is the foundation of a prosperous, patriotic, humanist-oriented nation. [1, p. 2422; 16, p. 2638; 19, p. 2690; 30, p. 1017].

Considering that the Olympic education is a pedagogical process that is implemented at all levels of education, and school age is one of the crucial (most important) periods in shaping the physical, moral and spiritual development of the child, it is worth noting the expediency of the Olympic education of pupils $[2$, p. $7 ; 8$, p. 44; 17, p. 75]. As at school age the child's body is actively developing, cognitive qualities and interests are forming, motor skills, moral and social principles of behavior are rapidly developing.

\section{The structure of the Olympic education in the educational process}

In recent times, many scholars and educators draw their attention to the need for significant increasing of the proportion of information, explanatory work on physical education lessons, physical education classes at schools, higher educational institutions and other educational institutions.

Thus, the classes organized for the following purposes - "Olympic lessons", "lessons of the Olympic knowledge", "Olympic hours", etc. are more and more widespread.

Many countries have prepared various methodological materials, including movies and video files, to promote the ideas of Olympism. Work on the creation of such programs and materials is also ongoing in Ukraine.

Many scientists and experts believe, that to improve efficiency in promoting the ideas of Olympism, propaganda must be carried out not only in education, directly related to the field of physical culture and sports, but also in other disciplines, especially humanitarian $[1$, p. $2424 ; 5$, p. 800; 14, p. 895].

The phenomenon of modern pedagogical reality, implementing the integrity of the educational process, is a real existing educational system. They become the object of investigation for many scientists and practitioners, 


\section{Olympic education in the educational process of Ukraine (in the case of...}

as actually performing a complete pedagogical process. Speaking about modern educational systems, it should be noted, that authoring systems of human upbringing as a phenomenon is not so frequent. Among all the studied works on the theory and practice of educational systems, the main direction proposed by members of the National Academy of Sciences of Ukraine, professors V.A. Karakovsky and L. I. Novikova was determined. Scientists claimed, that the basis of the activities of teachers, children and studying youth should lie in a set of ideas that define the future of educational institutions and creating in it an educational system [9, p.7]. It is necessary, that these ideas were inspired by the spirit of humanism and aimed children at mastering universal values, so that the relationships created in this activity, between the adults and children were humanistic, so that the pupils will not be isolated from the environment, but connected with it, connected reasonably, taking into account the peculiarity of this environment. In the base of the Olympic education and upbringing as an educational system lie humanistic ideas of the philosophy of Olympism, developed by Pierre de Coubertin. The educational system is complex psychological, socio-pedagogical education, that is uneven, self-regulating and controlling. This system is open: it not only successfully interacts with close and distant societies, but, mastering them, it becomes a powerful means of socialization. The educational system has a complex structure, it consists of components, fastened by system bonds. The connection of parts of the system into a single unit and facilitate the implementation of the Olympic education. Since these definitions, when modeling the educational system have a deep, theoretical sense, we denote the educational process as a holistic system.

In this case, the system forming element of the educational system can be considered not as a leading activity, but as the goals of education, and all the rest - means, content, forms, methods, activities, external and internal environment, system of relations, - organizational conditions that ensure the realization of goals. The scheme: the goal - the result, this is the essence of the system process. Often there is a too narrow interpretation of the upbringing goals of the Olympic education [4, p. 265]: the pedagogical goals of the Olympic movement are associated with "the upbringing of a moral and aesthetic attitude towards sport". However, in addition to the development of physical and moral qualities in pedagogical activity, it is equally important to form and develop the intellectual, aesthetic, communicative personality traits. V.M. Ermolova (2011) claims, that the objective 
of Olympic education and upbringing is to promote the implementation of the basic principles and ideas of Olympism, the Olympic Movement and the Olympic Games, which derive from their historical essence and defined today by the Olympic Charter, through a humanist organized pedagogical process, when the student voluntarily acquires knowledge and values that become the true motives of his behavior [12, p. 335]. Of course, in this definition, there is no end result of pedagogical activity aimed at attracting the younger generation to the ideals and values of Olympism. According to academician A.O. Bodnar (2014), "The central point for the system is the result, as any complex and any set become the system only through the result. At the same time, the system can not be stable, if the result itself does not affect the system of inverse afferentation with its existing parameters" [4, p. 267]. The purpose of the Olympic education and upbringing as an educational system is the formation of an Olympic culture. In this case, specialists offer to interpret this concept in different ways. L.I. Lubysheva understands Olympic culture as the specific philosophy of life, which includes the spiritual content of sport [21, p. 38]. It is also noted, that the phenomenon of Olympic culture is a developing complex of accumulated by humanity knowledge, norms, values, meanings, patterns of behavior, on the basis of which the humanistic way of life of society and personal life style are formed. Due to this phenomenon the mechanism of transmission through the channels of cultural continuity of the accumulated and developing by the humanity Olympic values from generation to generation works [21, p. 36]. This definition is quite complex and voluminous. That is why, V.I. Stolyarov simplifies it and states that Olympic culture is the complex of knowledge related to the ideals and values of Olympism, interests, needs, skills and habits on the basis of which a healthy lifestyle is formed $[25$, p. 26].

Pedagogical activity aimed at forming an olympic culture in the younger generation is rather complicated, and connected with the formation of the upbringing space and the development of certain relations. At the same time Ya. B. Zoriy (2016) has identified only a few modern programs of Olympic education, within which the pedagogical activity is aimed at the formation of an Olympic culture (Olympic education, upbringing in a broad pedagogical sense).

In the content of the "Spartans friends" program, written by O.V. Kozyreva and V.I. Stolyarov, the main forms and methods of preparing preschool chil- 


\section{Olympic education in the educational process of Ukraine (in the case of...}

dren for the Spartan Games (tournaments), as well as the methods for conducting them were included. O.V. Kozyreva and V.I. Stolyarov claim, that in the course of preparation for games it is especially important to attract children to the world of physical culture, sports and art, as well as the orientation towards behavior, according to humanistic principles [25, p. 127]. Preparations for games are carried out both in kindergartens (at lessons) and at home. For this purpose, teachers together with parents create for each child an individual program of his personal development, health promotion, improvement of motor abilities, mental qualities, skills in the field of sports and art, expansion and deepening of knowledge, etc. O.V. Kozyreva and V.I. Stolyarov point out, that there are great opportunities for joining the work due to the "Spartans friends" program, with the work based on the Olympic educa-tion and upbringing, proposed in the V.I. Usakov. In his program "Working with the Olympic and pre-school education" V.I. Usakov proposes to use the method of preparation and holding small Olympic Games for implementation the Olympic education for pre-schoolers $[27$, p. 38]. The main forms of work that this program offers are: Olympic lessons, small Olympic games that combine various contests and sport competitions, as well as creative work in the only one in the world, the children's theater named after Pierre de Coubertin.

A great attention is paid to the health keeping program, which is realized at the expense of a scientifically substantiated complex of systemic measures that eliminate the causes of deteriorating the health of pre-school children. Therefore, the results of the implementation of this program show that with the help of the method proposed in it, teachers can not only contribute to the formation and improvement of the system of knowledge and motivation in preschoolers in the field of Olympism and the Olympic movement, but also improve children's health. And this, in turn, leads to the formation of a personal style of life in preschoolers. Must be admitted, that the creators of "Spartans friends" and "Working with the Olympic and pre-school education" consider it necessary to prepare staff for their implementation. In the program of V.I. Usakov variants of training was not revealed, when in the program written by O.I. Kozyreva and V.I. Stolyarov, for this purpose, workshops for kindergarten workers were suggested [25, p. 26].

For a non-sporting higher educational institution, a program consists of two complementary parts: 1 . The section of theoretical training, which is proposed to be carried out during theoretical lessons (lectures, seminars), 
and in the first 3-5 minutes of practical classes. Furthermore, during sport events - "Olympic Days" and meetings with major athletes - great attention is paid for promoting of Olympic ideals and values. An important role is assigned to the use of means of visual agitation - posters, stands with Olympic symbols, containing both the best student results and the results of the Olympic records. 2. The section of the organization of motor activity of students, which is realized through a well thought out system of training and competitions. The main competitions in this university are University Spartakiad and Spartan Games. It is important to note, that the results of the implementation of other programs that would contribute to the formation of Olympic education in a broad pedagogical sense for students in non-sporting universities.

Upbringing expansion in olympic education - the result of the purposeful activity of all those interested in its creation: teachers, cultural workers, social workers, doctors. In this case, the upbringing expansion is multidimensional and multi-level. The main purpose of the upbringing expansion of the Olympic education and upbringing - to provide a higher degree of coordination of interaction between children and young people with nature, society and with oneself. The upbringing expansion of the Olympic education and education creates external conditions, that contribute to self-realization at the personal level. "Outside" management of the development of the Olympic education and upbringing as an educational system should take place in the upbringing expansion and be carried out taking into account the principle of regionality. This principle requires, that the content, methods, forms of education and upbringing correspond to the level of development and identity of culture, economy, peculiarities of nature, historical background, mentality, social and interpersonal relations in the region. The nucleus of the Olympic education and upbringing as an educational system is its collective subject - the educational collective. The people it unites, can set their own subjective goals, but the objective development of the system requires the creation of such a microclimate, at which all the entrances to the system would feel comfortable. For this purpose, the system "grows" children and forms the behavior of its members un such a way, that they can live and work in this system and promote its further development. In essence, for its members, the educational system is the sphere of relations that arises in a single educational group in the course of activities to achieve the goals. Relationships are widely consid- 


\section{Olympic education in the educational process of Ukraine (in the case of...}

ered here: not only interpersonal, but also to oneself, to nature, to the subject world, to spiritual values, to the environment, etc. Within the framework of the Olympic education and upbringing as an educational system in the process of activity and free communication, relations between the younger generations and their various communities are formed, between children and adults (educators, parents). As the analysis shows, they are the main factor of the system. The effectiveness of the Olympic education and upbringing depends on their character, to what extent they are humanistic. The main difference between the modern, humanistic educational system on the principles of Olympism from the authoritarian is, that everything here is created for the sake of the child himself, which serves as the subject of education. Both educators and students specify the objectives facing the school, transform them into a rank of practical tasks and carry out in the process of joint activity. The unification of children and adults into a single collective is the most important condition and result of the development of the modern educational system of the school.

It is generally acknowledged, that in order to implement the ideas of Olympism it is necessary to use not only educational, but also extra-curricular time. In practice, various forms of such work have been tested: the Olympic Day, the production of Olympic symbols, films and slides, as well as competitions in drawings, photographs, theatrical performances on the sports and Olympic themes, the design of stands, and even "Olympic halls", lectures, seminars, debates, discussions, conferences, Olympic quizzes, discussion of interesting books or films dedicated to sports, the Olympic Games, the organization of competitions among the excellent students for the title "Most Sporting Excellence", the organization of boards of honor for students who successfully combine studying, sports and social activity, the creation of Olympic museums, organization of correspondence with pupils, students, athletes from other countries interested in the problems of the Olympic movement, meetings with famous athletes, participants of the Olympic games and coaches of teams, organization of assistance the veterans of sports, former Olympians, etc.

Unfortunately, in the real practice of pedagogical work within the frame-work of the Olympic movement, there is an excessive passion for the enlightenment approach. Sometimes the goals and objectives of this work in general are reduced to the task of forming the Olympic education in children and youth. At the same time, it is often unreasonable to hope that by 
means of explanatory work, on the basis of lectures, conversations during the "Olympic lessons", "lessons of the Olympic knowledge", "Olympic hours" with the help of only mottos and calls will be able to solve the problem of attraction the rising generation to the ideals and values of Olympism.

In recent years, sporting competitions have become more widely used to promote the ideas of Olympism among children and young people. During these competitions, the Olympic attributes are used: the rising of Olympic flag, the Olympic oath, the Olympic firing ceremony, and others. Also, "Small Olympiads", "Olympic miles" and other Olympic competitions for children, teenagers and youth are regularly held.

However, in practice, the traditional model of organization of sports competitions, including the Olympic, contests, is based on strict rivalry of participants, encourage a small group of winners to demonstrate their superiority over others, win valuable prizes, rewards, get other material benefits associated with the victory. Therefore, using the traditional model of organization of sports, there are very significant difficulties in attracting children and youth to the spiritual, moral and aesthetic values of Olympism.

The above-mentioned negative features of the traditional model encourage to search and practically use in working with children and youth of new models of organization and holding of competitions that meet the goals and objectives of the Olympic education: orient the participants on the spiritual, moral and aesthetic values, rather than develop the desire to win at any price, do not give cause to violence, rudeness, aggressiveness, nationalism; form the desire for self-improvement, harmonious development.

The issue of Olympic topics is also reflected in the program "Physical Culture" for general education institutions, 1-11grades. The program includes the following topics: "Athletics competitions in the program of the Olympic Games" (Grade 3), "Prerequisites for the emergence of physical exercises. Healthy Lifestyle" (Grade 5), "Physical Education in Ancient Greece. The value of physical culture and sport to maintain mental performance. Aesthetic education in the process of physical education" (Grade 6), "Olympic Games of Ancient Greece. Principles of a healthy lifestyle" (Grade 7), "Revival of the Olympic Games of our time. Wellness systems and their role in health promotion. Fatal impact of harmful habits" (Grade 8), "Humanistic ideas of olympism. Health systems as a means of satisfaction of personal interests and motivations" (Grade 9), "History of sports development in Ukraine. Achievements of Ukrainian athletes on the 


\section{Olympic education in the educational process of Ukraine (in the case of...}

international scene. Factors that determine the effectiveness of competitive activities" (Grade 10), "Development of Physical Culture and Sports in Ukraine. Ukrainian athletes in the Olympic movement. Olympic sport at the present stage" (Grade 11) [8, p. 44].

At the initiative of the NOC of Ukraine from 2005 (in accordance with the Concept), every year on the eve of the Day of Physical Culture and Sports in educational institutions, Olympic lessons are held. Their content include informing students about the Olympic Games of Ancient Greece, the revival of modern Olympic games, the Olympic sport at the present stage, the importance of sport for the strengthening of peace and friendship among peoples, the problems of doping in sports, the environmental aspects of the Olympic movement, etc., holding small Olympic games with the observance of Olympic rituals, meeting with participants and medalists of the Olympic Games, outstanding trainers, veterans of sports, representatives of mass media, creative intellectuals, which activities are associated with sports topics. Since 2006, the All-Ukrainian Olympic lesson has gone beyond the school and began to take place on the central streets of the regional centers and Independence Square in the capital of Ukraine in Kyiv.

The main goal of the All-Ukrainian Olympic lesson is the education and upbringing of pupils in the humanistic values of the Olympic movement, formation of their skills and culture in a healthy way of life, engaging of them in active physical education and sports activities.

During the Olympic lesson, the Olympic symbols are used, while holding in the form of competitions - Olympic ceremonies and rituals: a solemn opening ceremony, a relay race of Olympic fire, inflammation of the Olympic flame, the raising of the Olympic flag, the swearing of the participants and judges, the ceremony of awarding and the solemn closing ceremony.

Also in schools, the Olympic Week is held, usually in September, starting with the Day of Physical Culture and Sports. Its main goal is to spread the ideas of Olympism, the development of the Olympic movement in Ukraine, the involvement of young people in systematic physical education and sports. The program of the Olympic week includes sports and entertainment events, the mandatory elements of which are the holding of Olympic sports, seminars, conferences, forums, contests related to the development and promotion of the Olympic movement.

Specialized higher education institutions of Ukraine introduced a special educational discipline "Olympic Sport", which became mandatory 
for students of all forms of education and postgraduate students. The course of Olympic Week includes topics devoted to the Olympic Games in ancient Greece, the revival of the Olympic Games, contemporary Olympic Games, Olympic ideals and values, the Olympic movement in Ukraine, the structure of the international Olympic movement, the legal basis of the Olympic movement, economic programs of the Olympic movement, Olympic sports and politics, history and trends in the programs of the Olympic Games, Olympic education, topical issues of the modern Olympic movement.

The discipline "Olympic sport" has been included in the curriculum of five specialized higher education institutions and thirty one higher educational institutions, in the structure of which there are faculties that educate specialists in the field of physical education and sports.

It should be noted, that a significant role in the work of higher educational institutions is played by cooperation with the secondary schools of Ukraine, which is realized in the following forms: organization and conducting of lectures, round tables, seminars on the Olympic theme for teachers of secondary schools; holding talks, lectures on the issues of Olympic sports and Olympic education with students; organization in contemporary educational institutions of sports holidays, meetings with prominent athletes.

\section{The state of readiness for the implementation of the Olympic educa-tion in Chernivtsi}

In the course of investigation, that was conducted in order to determine the status of the implementation of the Olympic education in the educational process, the questionnaire of teachers of physical culture in pre-school educational institutions, teachers of physical culture in schools and teachers of physical education in the higher educational institutions was made.

In the survey took part 75 respondents, (25 of which were instructors of physical education in the pre-school educational institutions, 25 - teachers of physical education and 25 - teachers of physical education at university level). The average work experience of respondents from pre-school educational institutions was 20 years, from secondary schools -8 years, from universities -14 years.

When answering the questionnaire, a method of ranking, the evaluation of objects by rank due to their significance, was offered to the respondents. 


\section{Olympic education in the educational process of Ukraine (in the case of...}

The place occupied by each of the selected objects was determined by the number of points he scored.

The majority of respondents believe, that the Olympic education can serve as an effective means of solving the problem of raising children and youth (206 points out of 250 possible, which is $82 \%$ ).

The Group of experts from pre-school institutions assessed the level of implementation of the Olympic education: most experts have identified a high level of implementation (80\%) and others (20\%) as the average level of implementation.

Analysis of application of physical education instructors in the preschool institutions allows to mark the shortcomings in the organization of Olympic education, namely: the low level of qualifications of personnel (56.8\%), lack of material-technical base (68.8\%), insufficient methodological support (60.8\%) low level of knowledge of professionals (54\%).

The main factors, according to experts, that interfere the implementation of the Olympic education are: the low level of children's motivation (62\%), low level of physical health of children (52\%), lack of reliable information about the health status of children (38\%), low interest in material aspect of the instructor of physical culture (52\%), insufficient material-technical base $(81 \%)$.

Analyzing the level of implementation of the Olympic education in schools, it is worth noting that no one has mentioned it as low. Instead, $60 \%$ of respondents noted a high level of implementation of the Olympic education and $40 \%$ average.

We consider it expedient to note, that $60 \%$ of teachers of physical culture consider it inappropriate to implement in the educational plan of the tutor the section "Olympic education".

Instead, respondents from universities talk about the expediency of introducing into the program the section "Olympic education" $(58 \%)$

Assessing the level of implementation of Olympic education in their educational institution, respondents from higher education institutions assessed: high (55\%) and average (45\%).

Analyzing the applications of instructors of physical culture children's educational institutions, teachers of physical education in schools and teachers of physical education in higher education institutions, we can make the following conclusions:

Most of the respondents believe, that the introduction of Olympic education will serve as an ideological moral basis for the upbringing of the 
younger generation (88\%). Thus, the results of the study confirm the importance of the integration of Olympic education in the educational process and its role in shaping the harmoniously developed personality.

Teachers have identified the most acceptable, in their opinion, the forms of the introduction of Olympic education in the educational process during the lessons and in extra time.

\section{A comparative analysis of Olympic education in schools}

During the survey, the level of implementation of Olympic education in educational institutions was assessed. Based on the results, we can conclude that the highest rating of the implementation of the Olympic education in educational institutions gave the respondents from the pre-school establishments of Chernivtsi city, where, according to the survey, the level of implementation of the Olympic education in educational process is $80 \%$.

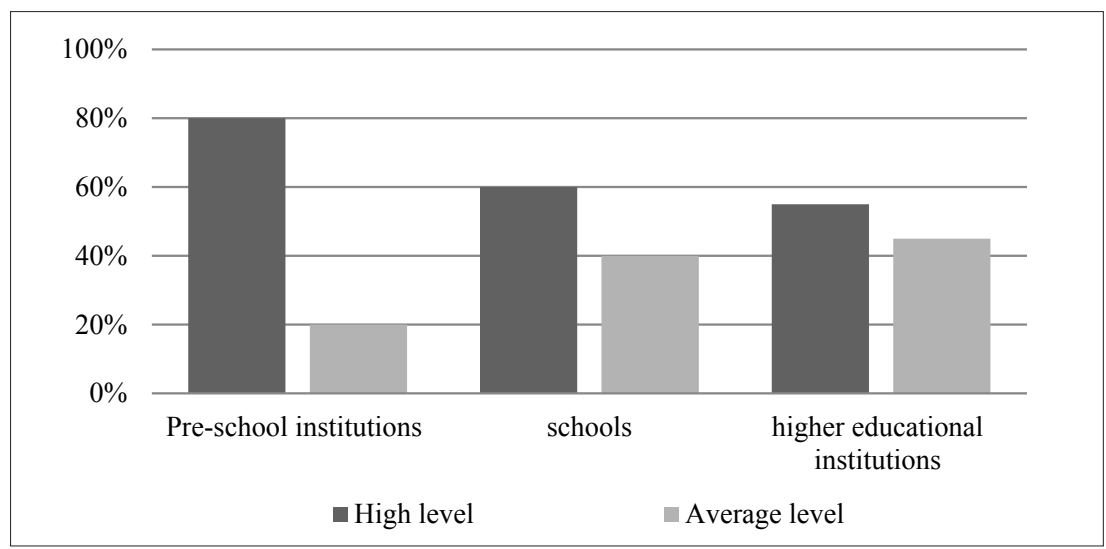

Fig. 1. Comparative analysis of the implementation of $\mathrm{OE}$ in educational institutions in Chernivtsi

In second place regarding the level of implementation of the Olympic education in Chernivtsi - comprehensive educational institutions (60\%), and the lowest level of implementation of the Olympic education in the educational process is in higher educational establishments - 55\% (fig. 1).

The majority of respondents believe, that the Olympic education can serve as an effective means of solving the problem of raising children and 
youth.They claim, that the implementation of the Olympic education in the educational process will contribute to: stabilization of psychophysical parameters $(74 \%)$, increasing motor activity (97\%), increasing interest in systematic physical training $(82 \%)$ increasing the level of physical health (89\%), improving health, activity and mood (95\%).

Answers of respondents gave an opportunity to identify the most acceptable, in their opinion, the forms of the introduction of Olympic education (Fig. 2).

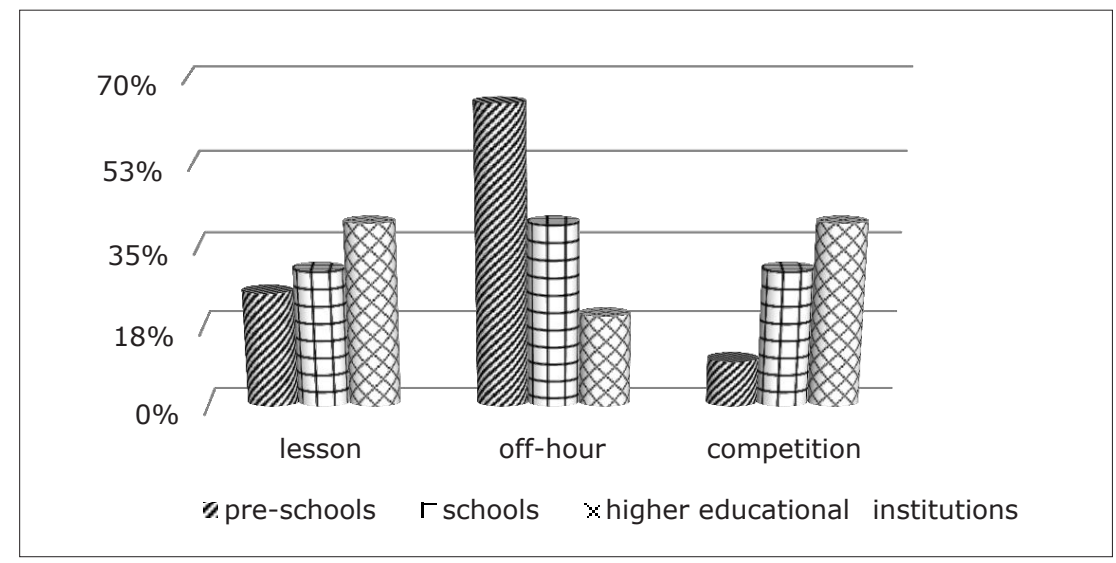

Fig. 2. The most effective forms of the introduction of Olympic educa-tion

So, in pre-schools, as the survey shows, $65 \%$ of the respondents find the most effective training - of the form of off-hour activities, according to the $25 \%$ of the respondents is the activities during the lesson, and only $10 \%$ noted competitive form. Regarding the forms of implementation of the Olympic education in schools, the opinions of respondents are divided as follows: $30 \%$ - during lesson, $40 \%$-off-hour, 30\% - and competitive. Respondents ' opinions from the University level diverged a bit differently: $40 \%$ - during lesson, $20 \%$ - off-hour, $40 \%$ - and during competition time. As you can see, the off-hour form for the implementation of the Olympic education, according to the respondents, are more effective for children of pre-school age, and for older student competitive form will be more interesting. 


\section{Survey methodology}

The following research methods were used during the research: theoretical analysis and generalization of literary sources, conversation, expert estimation, methods of mathematical statistics.

The investigation was conducted during 2016-2017 in various educational institution in Chernivtsi. We conducted a ascertaining experiment to create a database necessary for studying the formation and implementation of Olympic education in educational institutions of Ukraine. Conduction of a survey of experts aimed at identifying the factors that best influence the implementation of the OE. In the survey took part 75 respondents, 25 of which were instructors of physical education in the pre-school educational institutions, 25 - teachers of physical education and 25 - teachers of physical education at university level.

The expert questionnaire consisted of 15 questions. The first part was of an informative nature, because the position and experience of the respondent's work and so on were studied. The second part of the questions was to determine the status of the implementation of the Olympic education in schools. The final part included questions that were aimed at sharing and popularizing of the Olympic education among the younger generation. The obtained data made it possible to determine the conditions for the optimal implementation of OE in educational institutions.

\section{Conclusions}

Creation of a modern system of education and upbringing of the younger generation is impossible without the optimal solution of a range of social, economic, environmental, political, legal and other tasks. One of the solutions of this difficult problem may be the organization of an educational process based on the ideology of Olympism, through the introduction of a system of Olympic education and the dissemination of literature among the student youth.

Olympic education, as an effective means of raising children and young people, has deep historical background. Its dynamics can be represented in the form of three successive stages: the first - the origins of the idea of the Olympic education; the second - the formation of its foundations; the third - the implementation and the development.

The implementation of Olympic education in the educational process of children and youth is carried out through the introduction of innovative 


\section{Olympic education in the educational process of Ukraine (in the case of...}

projects, the use of methodological aids, the use of various forms of dissemination of Olympic ideas.

The popularization of Olympic ideas, the implementation of Olympic education among the general population and, especially, among children, adolescents and young people are possible by: introduction of methodological recommendations, aimed at the relationship of educational material with Olympic ideals, in training programs of physical education and other disciplines; the usage of a differentiated approach for the dissemination of Olympic knowledge; utilizing of special situational tasks, role-playing games in the preparation of teaching staff.

The level of implementation of Olympic education in the educational process of educational institutions of Ukraine in Chernivtsi is the highest in the preschools, the highest rates - universities.

The attitude of physical education teachers and instructors of physical education to the implementation of Olympic education in the educational process of an educational institution is rather positive. They believes that the introduction of Olympic education will serve as the ideological moral basis of the process of upbringing of the younger generation (88\%). Thus, the results of the study confirm the importance of integrating the Olympic education into the educational process and its role in the formation of a harmoniously developed personality

A perspective direction of work will be the further study of the peculiarities of the introduction of Olympic education in the process of upbringing children and youth of different age groups, developing the structure and content of the Olympic education, recommendations for their further implementation.

\section{References:}

1. Andrieieva O., Hakman A., Balatska L., Moseychuk Y., Vaskan I. \& Kljus O. (2017). Peculiarities of physical activity regimen of 11-14-year-old children during curricular and extracurricular hours. Journal of Physical Education and Sport, 17 (4), 2422-2427. doi:10.7752/jpes.2017.04269

2. Andrieieva,O., GalanY., Hakman, A., \& Holovach, I. (2017). Application of ecological tourism in physical education of primary school agechildren. Journal of Physical Education and Sport, 17 (1), 7-15. DOI:10.7752/jpes.2017.s1002

3. Balatskaya L., Hakman A., Nakonechny I. \& Vaskan I. (2016). Socioeconomic development of the country as a means of influencing the Olympic movement and physical culture. Sports. Olympism. Health : Endorsed the 65th anniversary of the organization of the Higher Education of Physical Culture of the Republic of Moldova: International Scientific Congress, 5-8. October 2016: 137-141. 
4. Bodnar A.O. \& Solopchuk M.S. (2014). Study of the level of formation of Olympic education in students of physical education faculties of higher educational institutions. Bulletin of the Kamyanets-Podilsky National University. Physical education, sports and human health. Whip 7: 265-272.

5. Bohuslavska V., Furman Y., Pityn M., Galan Y., Nakonechnyi I. (2017). Improvement of the physical preparedness of canoe oarsmen by applying different modes of training loads. Journal of Physical Education and Sport, 17 (2), 797-803. DOI:10.7752/jpes.2017.02121

6. Bulatova M. (2007). Olympic Academy of Ukraine: priority areas of activity. Science in the Olympic sport. 2007. № 2: 5-12.

7. Bulatova M. (2008). Olympism as a universal concept of education and youth education. Physical education at school № 1 (51) 2008: pp. 40-43.

8. Bulatova M.M. \& Yermolova M.V. (2007). Olympic education in the system of educational work of general educational institutions of Ukraine. Olympic literature, 2007: 44.

9. Bulatova M.M. (2005). The system of Olympic education and new forms of its implementation. Olympic Sports and Sports for All: Abstracts of the IX International Scientific Congress: 7.

10. Bulatova M.M. (2006). The system of Olympic education in Ukraine (1991-2006): methodology and practical results. Modern Olympic sports and sport for all: Materials X International. sci. Congress: Gdansk, 2006: 38-41.

11. Bulatova M.M. (2007). Olympic Academy of Ukraine: priority directions of activity. Science in Olympics. 2007. Number 2: 5-12.

12. Ermolova V.M. Olympic Education: Theory and Practice: Teach. Manual K., 2011: 335.

13. Galan Ya., Kirilyuk M. \& Kochubei M. (2015). Implementation of the Olympic education in vocational schools of Bukovina. Materials of the IV International Scientific and Practical Conference, November 5-6, 2015, Chernivtsi: 204-206.

14. Gorshova I., Bohuslavska V., Furman Y., Galan Y., Nakonechnyi I., Pityn M. (2017). Improvement of adolescents adaptation to the adverse meteorological situationby means of physical education. Journal of Physical Education and Sport, 17 (2), 892-898. DOI:10.7752/jpes.2017.02136

15. Hakman A. \& Krushelnytsky B. (2017). Olympic education as a component of the humanitarian education of the younger generation. "Physical culture and sport: experience and perspectives: materials of the international scientific and practical conference (Chernivtsi, April 6-7, 2017)«: 18-20.

16. Hakman A., Nakonechniy I., Moseychuk Y., Liasota T., Palichuk Y. \& Vaskan I. (2017). Training methodology and didactic bases of technical movements of 9-11- year-old volleyball players. Journal of Physical Education and Sport, 17 (4), 2638 - 2642. doi:10.7752/jpes.2017.04302

17. Hakman A.V. \& Krushelnytsky B.M. (2017). The status of the implementation of Olympic education in the educational process (for example, the city of Chernivtsi). Young Scientist, 2017/3 (43): 74-77.

18. Hruzevych I., Bohuslavska V., Kropta R., Galan Y., Nakonechnyi I., Pityn M. (2017) The effectiveness of the endogenous-hypoxic breathing in the physical 


\section{Olympic education in the educational process of Ukraine (in the case of...}

training of skilled swimmers. Journal of Physical Education and Sport (JPES), 17 (Supplement issue 3), 1009-1016. doi:10.7752/jpes.2017.s3155

19. Iedynak G., Galamandjuk L., Kyselytsia O., Nakonechnyi I., Hakman A. \& Chopik O. (2017). Special aspects of changes in physical readiness indicators of young men with different somatotypes between 15 and 17 years of age. Journal of Physical Education and Sport, 17 (4), 2690 - 2696. doi:10.7752/jpes.2017.04311

20. Ivashchenko, O., Yarmak, O., Galan, Y., Nakonechnyi, I., \& Zoriy, Y. (2017). Leadership as a fundamental aspect of the performance of student-athletes in university men's sports teams. Journal of Physical Education and Sport, 17, Supplement issue 2, 472-480. DOI:10.7752/jpes.2017.s2071

21. Lubysheva L.I. (2007). Integration of sports and Olympic education in the educational space of the school. Science in the Olympic sport. 2007. № 2: 36-40.

22. Nakonechnyi I., Galan Y. (2017). Development of behavioural self-regulation of adolescents in the process of mastering martial arts. Journal of Physical Education and Sport, 17, Supplement issue 3, 1002-1008. DOI:10.7752/jpes.2017.s3154

23. Platonov V.N. \& Guskov S. I. (1994). Olympic sport: In 2 tons. Olympic Literature. 1994. Book 1.: 494; 1997. Book 2: 384.

24. Stolbov V.V. (1996). The evolution of the Olympic ideas from Pierre de Coubertin to Juan Antonio Samaranch. Olympic movement and social processes: materials V Vseros. scientific and practical work. Conf., dedicated to the 100th anniversary of Intern. Olympus. Of the Committee: 22-28.

25. Stolyarov V.I. \& Barinova I.V. (2002). System of Olympic education, education and training of youth (content and ways of formation). Materials conf. "The practice of Olympic education in the II International. Forum "Youth-Science-Olympism: 125-127.

26. Sunik A.B. (1991). "Olympic memoirs" by Pierre de Coubertin as a source of studying the history of the Olympic movement. Olympic Movement and social processes: Mat. All-Russ. Conf. Chelyabinsk:.39-50

27. Tomenko O. (2008). Features of the Olympic Education in the PRC on the eve of the Games of the XXIX Olympiad in Beijing. Theory and methods of physical education and sport. 2008. Number 3: 36-40.

28. Vaseba O. \& Yukhimchuk V. (2007). Topical issues of Olympic education in the educational process of students of general education schools in Ukraine (for example, Lviv). Materials of continental seminar "Olympic education: upbringing, healthy lifestyle, social adaptation". K., 2007: 87-93.

29. Yarmak, O., Galan, Y., Hakman, A., Dotsyuk, L., Blagii, O. \& Teslitskyi Yu. (2017). The Use of Modern Means of Health Improving Fitness during the Process of Physical Education of Student Youth. Journal of Physical Education and Sport, 17 (3). 1935-1940. doi:10.7752/jpes.2017.03189

30. Yarmak, O., Galan, Y., Nakonechnyi, I., Hakman, A., Filak, Y. \& Blahii, O. (2017). Screening System of the Physical Condition of Boys Aged 15-17 Years in the Process of Physical Education. Journal of Physical Education and Sport, 17 Supplement Issue 3, 1017-1023. doi:10.7752/jpes.2017.s3156

31. Zoriy Ya. B. \& Hakman. A.V. (2016). The system of Olympic education as a means of pedagogical process of the younger generation. Scientific journal of NP Drahomanov NPP. Series 15: Scientific and pedagogical problems of physical culture (physical culture and sports). No. 4: 33-35. 